\title{
PELAKSANAAN KEPENGAWASAN MELALUI METODE SUPERVISI TIDAK LANGSUNG DENGAN PENDEKATAN LEADERSHIP 3.0 PADA SEKOLAH KHUSUS ( BEST PRACTICES)
}

\author{
Dra. Kustiatun Widianingsih, M.Phil.SNE \\ NIP. 195909301983122001
}

\begin{abstract}
Abstrak:
Penyelenggaraan pendidikan merupakan tanggung jawab bersama antara pemerintah, masyarakat dan keluarga. Masing-masing memiliki peran yang sangat besar dalam rangka mewujudkan tujuan pendidikan. Dalam melakukan tugas pokoknya seorang pengawas harus melakukan pembinaan, pemantauan dan penilaian penyelenggaraan pendidikan pada sekolah binaannya baik negeri maupun swasta yang menjadi tanggung jawabnya dengan melalui supervisi langsung maupun tidak langsung. Best practice ini dengan judul Strategi Pelayanan Kepengawasan Melalui Metode Supervisi Tidak Langsung Dengan Pendekatan Leadership 3.0 Untuk Meningkatkan Kinerja Kepala Sekolah Pendidikan Khusus. Studi Kasus Layanan Kepengawasan Pendidikan Khusus Di Kabupaten Banyuwangi, Jawa Timur Tahun 2013/2017, dengan rumusan permasalahan bagaimana strategi pelayanan kepengawasan melalui Metode supervise tidak langsung dengan pendekatan Leadership 3.0 studi kasus layanan Kepengawasan Pendidikan Khusus dapat meningkatkan Kinerja Kepala Sekolah dan guru Pendidikan Khusus.

Dari hasil best practices yang penulis lakukan bahwa dari jumlah 43 sekolah jenjang sekolah dari TKLB, SDLB, SMPLB dan SMALB baik swasta maupun negeri dinyatakan $75 \%$ berhasil dilakukan penilaian kinerja kepala sekolah melalui supervisi tidak langsung.

Dengan dilakukan pembinaan melalui pelayanan supervisi tidak langsung dan komunikasi secara efektif maka dapat dihasilkan adanya peningkatan pada sekolah TKLB, SDLB, SMPLB dan SMALB Kabupaten Banyuwangi Jawa Timur.
\end{abstract}

Kata Kunci : Strategi supervise tidak langsung, Leardership 3.0

\section{PENDAHULUAN}

Penulis seorang pengawas sekolah Pendidikan Khusus yang mendapatkan tugas kepengawasan di wilayah Kabupaten Probolinggo, Kabupaten Lumajang , Kabupaten Banyuwangi dan Kota Madiun. Salah satu tugas Pengawas Sekolah adalah melakukan pengawasan supervisi akademik, supervisi menejerial, pembimbingan dan pelatihan guru pendidikan khusus terhadap sekolah binaannya.

Sejak lima tahun berjalan penulis melakukan pelayanan pembinaan, pemantauan dan penilaian di sekolah binaan terutama di Kabupaten Banyuwangi banyak menemukan kendala. Hal ini dikarenakan jarak daerah dari tempat tinggal penulis kurang lebih $300 \mathrm{~km}$ dengan jumlah 43 sekolah baik negeri maupun swasta dari tingkat TKLB, SDLB, SMPLB 
Pelaksanaan Kepengawasan Melalui Metode Supervisi Tidak Langsung Dengan Pendekatan Leadership 3.0 Pada Sekolah Khusus (Best Practices)

dan SMALB. Sehingga pelaksanaan pelayanan kepengawasan tidak optimal baik dari supervisi manajerial, maupun supervisi akademik dan Program pembimbingan dan pelatihan kepala sekolah dan guru.

Hasil supervisi masih sangat kurang di Kabupaten Banyuwangi selama tiga tahun terhadap kepala sekolah. Skor hasil supervisi manajerial dalam 6 semester tahun 2013/2014, 2014/2015 dan 2015/2016 rerata 1,9 menunjukkan kategori kurang maksimal, karena skor maksimal adalah 3,0. Dan supervisi akademik 1,7 menunjukkan kategori kurang maksimal karena skor maksimal adalah 3,0. Hal ini disebabkan karena pembinaan yang kurang efektif, dan tidak dilakukan pelayanan kepemimpinan penulis dengan pendekatan yang optimal.

Penulis membaca teori tentang pendekatan kepemimpinan (Leardership) 3.0 menurut Ardhi Ridwansyah dalam bukunya Leadership 3.0 adalah kepemimpinan yang didasarkan pada kemampuan seseorang untuk menggerakkan orang lain di sekitarnya disini diartikan pengawas berperan sebagai seorang pelayan dengan secara suka rela orang-orang tersebut mengikutinya. Pengaruh sang pemimpin muncul dari karisma internal yang ditunjukkannya. Pendekatan ini diartikan bagaimana memengaruhi orang lain tanpa mengandalkan titel dan jabatan. Seperti yang dikemukakan oleh Stephen J.Sampson (2011) seorang psikolog di bidang Social Intelligence Skills bahwa ada enam aspek yaitu physicality, Sociability, Intellectuality, Emotionality, Personability dan Moral Ability, aspek physicality akan memengaruhi persepsi orang lain tentang kemampuan leadership kita. Sedangkan Intellectuality adalah kemampuan pengawas untuk mengelola cara berfikir sehingga bisa memberikan pengaruh yang lebih efektif kepada orang lain. Aspek emotionality terkait dengan manajemen emosi, atau kemampuan pengawas untuk mengelola emosi pribadi dan emosi orang lain sehingga dapat memengaruhi yang diberikan bisa lebih optimal.

Untuk mengatasi kendala, maka penulis melakukan tindakan supervisi tidak langsung dengan berbasis media blog. Dewasa ini di Kabupaten Banyuwangi dengan kemajuan teknologi informasi adanya program Banyuwangi 1100 wifi sangat mendukung adanya fasilitas yang mudah dengan jaringan telekomonikasi yang kuat sehingga sangat memudahkan penggunaan fasilitas internet, face book, twitter, dan sekolah memiliki fasilitas wifi. 


\section{TUJUAN}

1. Tercapainya Visi, Misi dan tujuan Kepengawasan

2. Optimalisasi pelaksanaan supervise manajerial dan akademik.

3. Peningkatan kompetensi kepala sekolah dan guru dalam penggunaan Teknologi Informatika

4. Inovasi pembinaan, pemantauan dan penilaian kepengawasan.

5. Meningkatkan standar nilai akreditasi sekolah yang telah dicapai

6. Meningkatkan komunikasi melalui media maya untuk ajang diskusi pengawas, kepala sekolah dan guru.

\section{STRATEGI PEMECAHAN MASALAH}

1. Dilakukan diskusi melalui media blog, internet, email, hand phone, face book tentang informasi kepengawasan yang berkaitan dengan supervise akademik, menejerial, dan pembimbingan dan pelatihan guru.

2. Pendekatan holistic leadership 3.0 dari aspek sosial, psikologis, komunikasi, psysicaly dan emosional dengan mengedepankan pelayanan bukan inspektorat atau pengawas sebagai boss tetapi pengawas sebagai pelayan yang harus melindungi, mengayomi, membimbing, meneladani, memberikan motivasi dengan melalui komunikasi media blog “MOZAIK PK BWI” sebagai wadah shering informasi antar kepala sekolah dan guru di Banyuwangi.

3. Melakukan supervisi tidak langsung pada setiap saat kita jadwalkan untuk online di media blog untuk pembinaan supervisi akademik dan menejerial atau memberikan informasi yang berkaitan dengan peningkatan kompetensi pengetahuan kepala sekolah dan guru.

\section{KAJIAN LITERATUR}

\section{A. Alasan Pemilihan Strategi}

1. Mengacu kepada visi, misi dan tujuan kepengawasan

2. Inovasi pembinaan, pemantauan dan penilaian supervisi untuk memudahkan melakukan program.

3. Mengoptimalkan pelaksanaan program supervisi

4. Menfasilitasi komunikasi pengawas, kepala sekolah dan guru di media maya

5. Peningkatan kompetensi kepala sekolah dan guru dalam mengases internet 
Pelaksanaan Kepengawasan Melalui Metode Supervisi Tidak Langsung Dengan Pendekatan Leadership 3.0 Pada Sekolah Khusus (Best Practices)

6. Menambah wawasan kepada kepala sekolah dan guru tentang perkembangan pendidikan.

\section{B. Hasil Atau Dampak Yang Dicapai}

1. Pengaruh aspek teori Leadership 3.0 bahwa Intellectuality adalah kemampuan pengawas untuk mengelola cara berfikir sehingga bisa memberikan pengaruh yang lebih efektif kepada orang lain. Dari dasar teori tersebut pada saat penulis memberikan pengaruh kepada kepala sekolah untuk mengikuti perintah yang berkaitan dengan kepengawasan tentang pengelolaan persiapan akreditasi sekolah dapat dihasilkan dari delapan Standar Nasional Pendidikan tahun pelajaran 2013/2014 adalah :

Table.1. Data sekolah yang telah terakreditasi adalah:

\begin{tabular}{|c|c|c|c|c|c|c|c|c|c|c|c|}
\hline \multirow[t]{2}{*}{ NO } & \multirow[t]{2}{*}{$\begin{array}{l}\text { JENJANG } \\
\text { SEKOLAJH }\end{array}$} & \multirow{2}{*}{$\begin{array}{l}\text { JMLH } \\
\text { Sekola } \\
\text { h }\end{array}$} & $\begin{array}{l}\text { Ket } \\
8 \mathrm{St}\end{array}$ & $\begin{array}{l}\text { rcap } \\
\text { anda }\end{array}$ & $\begin{array}{l}\text { aian } \\
\mathrm{Na}\end{array}$ & onal & end & dikar & & & \multirow[b]{2}{*}{$\begin{array}{l}\text { SKOR } \\
\text { persenta } \\
\text { se }\end{array}$} \\
\hline & & & S 1 & S 2 & S3 & S4 & S5 & S6 & S7 & S8 & \\
\hline 1 & TKLB & 10 & 6 & 6 & 7 & 8 & 6 & 8 & 6 & 7 & $72 \%$ \\
\hline 2 & SDLB & 18 & 16 & 16 & 17 & 17 & 16 & 17 & 18 & 18 & $75 \%$ \\
\hline 3 & SMPLB & 11 & 11 & 10 & 9 & 8 & 9 & 7 & 11 & 9 & $77,2 \%$ \\
\hline 4 & SMALB & 4 & 3 & 3 & 2 & 2 & 4 & 3 & 3 & 2 & $55 \%$ \\
\hline & JUMLAH & 43 & & & & & & & & & $68,5 \%$ \\
\hline
\end{tabular}


Table.2. Jenjang sekolah yang mencapai 8 SNP tahun 2013/2014 adalah

\begin{tabular}{|c|c|c|c|c|c|c|c|c|c|c|c|}
\hline \multirow[t]{2}{*}{ NO } & \multirow[t]{2}{*}{$\begin{array}{l}\text { JENJANG } \\
\text { SEKOLAJH }\end{array}$} & \multirow{2}{*}{$\begin{array}{l}\text { JMLH } \\
\text { Sekola } \\
\text { h }\end{array}$} & $\begin{array}{l}\text { Ket } \\
8 \mathrm{St}\end{array}$ & $\begin{array}{l}\text { ercap } \\
\text { anda }\end{array}$ & $\begin{array}{l}\text { aian } \\
\mathrm{Na}\end{array}$ & onal & enc & dikar & & & \multirow[b]{2}{*}{$\begin{array}{l}\text { SKOR } \\
\text { persen } \\
\text { tase }\end{array}$} \\
\hline & & & $\begin{array}{l}S \\
1\end{array}$ & S 2 & S3 & S4 & S5 & S6 & S7 & S8 & \\
\hline 1 & TKLB & 10 & 8 & 8 & 8 & 9 & 7 & 8 & 7 & 8 & $\begin{array}{l}78,79 \\
\%\end{array}$ \\
\hline 2 & SDLB & 18 & 18 & 17 & 17 & 17 & 17 & 17 & 18 & 18 & $\begin{array}{l}93,75 \\
\%\end{array}$ \\
\hline 3 & SMPLB & 11 & 11 & 10 & 10 & 10 & 9 & 10 & 11 & 10 & $77,5 \%$ \\
\hline 4 & SMALB & 4 & 4 & 4 & 3 & 3 & 4 & 3 & 3 & 3 & $\begin{array}{l}93,75 \\
\%\end{array}$ \\
\hline & JUMLAH & 43 & & & & & & & & & \\
\hline
\end{tabular}

Tabel ke 3 perkembangan 8 SNP dari tahun 2012/2013 dengan tahun 2013/2014

\begin{tabular}{|c|c|c|c|c|}
\hline NO & $\begin{array}{l}\text { JENJANG } \\
\text { SEKOLAH }\end{array}$ & $\begin{array}{l}\text { TAHUN } \\
2012 / 2013\end{array}$ & $\begin{array}{l}\text { TAHUN } 2013 \text { / } \\
2014\end{array}$ & $\begin{array}{l}\text { KETERANG } \\
\text { AN }\end{array}$ \\
\hline 1 & TKLB & $72 \%$ & $78,79 \%$ & $\begin{array}{l}\text { Ada kenaikan } \\
6,79 \% \text { dalam } \\
\text { tahun }\end{array}$ \\
\hline 2 & SDLB & $75 \%$ & $93,75 \%$ & $\begin{array}{l}18,75 \% \text { ada } \\
\text { kenaikan }\end{array}$ \\
\hline 3 & SMPLB & $77,2 \%$ & $77,5 \%$ & $\begin{array}{ll}0,3 \quad \% & \text { ada } \\
\text { kenaikan } & \end{array}$ \\
\hline 4 & SMALB & $55 \%$ & $93,75 \%$ & $\begin{array}{ll}28,75 \% & \text { ada } \\
\text { kenaikan } & \end{array}$ \\
\hline & & & & \\
\hline
\end{tabular}

Diskripsi kenaikan keberhasilan dari tahun 2014/2015 dan 2015/2016 adalah: TKLB $6,79 \%$, SDLB $18,75 \%$, SMPLB $0,3 \%$ dan SMALB $28,75 \%$ 
meningkatnya pengembangan sekolah berdasarkan 8 Standar Nasional Pendidikan. Telah terpenuhinya administrasi secara optimal sesuai kebutuhan karakteristik peserta didik contohnya bio data asessmen peserta didik, RPP, administrasi kesiswaan, KTSP ( Kurikulum Satuan Pendidikan) dan silabus. Terakomodatif data kepengawasan dari 8 SNP secara administratif di tiap-tiap sekolah setelah dilakukan analisis sehingga memudahkan pengolahan data pada setiap kebutuhan supervisi dengan menggunakan multi media. Dimudahkannya perolehan data dari sekolah binaan yang telah di simpan di blog data MOZAIK PK BWI

2. Pengaruh aspek emotionality terkait dengan manajemen emosi, atau kemampuan pengawas untuk mengelola emosi pribadi dan emosi orang lain sehingga dapat memengaruhi yang diberikan bisa lebih optimal. Hal ini dapat dilihat dari hasil kerutinitas kepala sekolah dan guru yang dapat dilihat hasilnya dalam kegiatan mengases internet sebagai berikut:

Tabel 4. Guru dan Kepala Sekolah yang mengases Internet ( email, Blog, HP )

\begin{tabular}{|l|l|l|l|l|l|}
\hline NO & $\begin{array}{l}\text { JUMLAH } \\
\text { SEKOLAH }\end{array}$ & $\begin{array}{l}\text { TH } \\
\mathbf{2 0 1 2 / 2 0 1 3}\end{array}$ & $\begin{array}{l}\text { TH } \\
\mathbf{2 0 1 3 / 2 0 1 4}\end{array}$ & JENIS YANG DI AKSES & $\begin{array}{l}\text { KET. } \\
\text { kenaikan }\end{array}$ \\
\hline 1 & $\mathbf{1 0}$ TKLB & 8 & 10 & Email, Blog, Hand Phone & $20 \%$ \\
\hline 2 & $\mathbf{1 8}$ SDLB & 10 & 16 & Email, blog, Hand Phone & $33 \%$ \\
\hline 3 & $\mathbf{1 1}$ SMPLB & 6 & 11 & $\begin{array}{l}\text { Email , Hand Phone, } \\
\text { Mozaik PK BWI }\end{array}$ & $45 \%$ \\
\hline 4 & $\mathbf{4}$ SMALB & 2 & 3 & $\begin{array}{l}\text { Email , Hand Phone, } \\
\text { Mozaik PK BWI }\end{array}$ & $25 \%$ \\
\hline
\end{tabular}

Diskripsi pengguna media maya dari jenjang TKLB, SDLB,SMPLB dan SMALB adalah:

Komunikasi kepala sekolah dan guru dengan efektif melalui internet, ( dunia maya), hand phone dan multi media yang lain yang diwadahi dengan MOZAIK PK BWI adalah TKLB 20\%, SDLB 33\%, SMPLB 45\% dan SMALB $25 \%$.

Selain aspek emotionality pengaruh kemampuan sociability aspek ini lebih sekedar kecerdasan emotional (EQ) yang terkait dengan kemampuan untuk membangun jaringan 
sosial sebagai modal untuk melebarkan pengaruh yang dimiliki. Disini penulis membuktikan bahwa media maya sangat memudahkan pengawas, kepala sekolah dan guru

berdialog, berkomunikasi, sharing informasi dan memberikan nilai positif untuk meningkatkan kompetensi mereka. Hasil dari jejaring ini dapat penulis sampaikan bahwa :

a. Adanya informasi permasalah sertifikasi, PLPG, study lanjutan untuk kepala sekolah atau guru yang belum S1 dengan latar belakang pendidikan PLB.

b. Informasi undangan pelatihan/ diklat yang diadakan daerah atau pusat yang berkaitan dengan informasi pelaksanaan.

3. Pengaruh kemampuan dalam aspek personalability lebih menekankan pada fondasi kepemimpinan yang terkait dengan kesadaran tentang hakikat diri serta visi-misi pribadi yang akan diemban dan disebarluaskan kepada orang lain. Pada aspek ini penulis telah melihat hasil dari proses kepengawasan selama 2 tahun bahwa:

a. Visi pengawas yang mewujudkan sistem pengawasan pendidikan dan pembinaan yang mampu mendorong penyelenggaraan dan pengelolaan Pendidikan yang efisien dan efektif serta bersih dari praktik korupsi, kolusi, dan nepotisme, sehingga dapat mendorong terwujudnya Pendidikan, yang bermutu, merata dan dapat dipertanggung-jawabkan.

b. Terwujudnya misi pengawas sekolah meningkatkan efektifitas pelaksanaan pengawasan yang berorientasi akuntabilitas; mencegah praktik korupsi, kolusi dan nepotisme; mendorong terwujudnya akuntabilitas unit kerja; meningkatkan profesionalisme kerja; mengembangkan sistem pengawasan yang lebih mandiri dan obyektif.

Data dapat penulis sampaikan dalam pembinaan bahwa:

Tabel 5. Terwujudnya pengelolaan sekolah dilihat dari Penilaian Kinerja Kepala Sekolah

\begin{tabular}{|l|l|l|l|l|}
\hline NO & $\begin{array}{l}\text { NAMA KEPALA } \\
\text { SEKOLAH }\end{array}$ & JENJANG SEKOLAH & HASIL & KET \\
\hline 1 & E N & SMALB.N & 85,35 & SB \\
\hline 2 & LM & SMPLB.N & 88,00 & SB \\
\hline 3 & SB & SDLB.C.N & 87,50 & SB \\
\hline 4 & KN & SDLB.A.N & 87,23 & SB \\
\hline
\end{tabular}


Pelaksanaan Kepengawasan Melalui Metode Supervisi Tidak Langsung Dengan Pendekatan Leadership 3.0 Pada Sekolah Khusus (Best Practices)

\begin{tabular}{|l|l|l|l|l|}
\hline 5 & SD & SDLB.B.N & 87,30 & SB \\
\hline 6 & MJ & SDLB ADELWIS & 86,96 & SB \\
\hline 7 & NH & SMALB ADELWIS & 90,35 & SB \\
\hline 10 & SW & TKLB PGRI ROGOJAMPI & 90,35 & SB \\
\hline 11 & WH & SMPLB PGRI ROGOJAMPI & 76,63 & B \\
\hline 12 & SB & SDLB PGRI ROGOJAMPI & 86,96 & SB \\
\hline 13 & NYH & SMPLB PGRI CLURING & 90,96 & SB \\
\hline 14 & HSS & SDLB PGRI CLURING & 87,08 & SB \\
\hline 15 & YS & TKLB PGRI CLURING & 79,00 & B \\
\hline 16 & BM & SDLB PGRI SINGOJURUH & 91,00 & SB \\
\hline 17 & TS & SMPLB PGRI SINGOJURUH & 90,56 & SB \\
\hline 18 & SW & SINLB ABCD PGRI & 77,20 & B \\
& & TKLB PGRI 2 JAJAG & 91,00 & SB \\
\hline 19 & SN & SDLB ABCD PGRI 2 JAJAG & 84,46 & SB \\
\hline 20 & ST & SMPLB PGRI 2 JAJAG & 90,56 & SB \\
\hline 21 & SM & JUMLAH & 164,845 & \\
\hline & & \multicolumn{2}{|l}{} \\
\hline
\end{tabular}

Total $: \underline{164,845 \times 100}=78,49($ baik $)$ rerata

Diskripsi : Dari 43 sekolah kepala sekolah yang telah dilakukan penilaian kinerja kepela sekolah adalah 21 sekolah TKLB,SDLB dan SMALB dengan nilai baik.

Berdasarkan pengaruh kemampuan dalam aspek moral ability yang dapat diimplementasikan dari fondasi seorang pengawas dalam kepemimpinan yang terkait dengan kemampuan untuk menjaga integritas moral sehingga pengaruh yang penulis berikan menjadi sustainable ( berefek jangka panjang ) . dari moral ability tersebut penulis telah mengimplementasikan melalui penilaian kinerja kepala sekolah dan penyusunan RPP.

Dengan hasil pembinaan melalui internet dapat penulis sampaikan hasil dokumen RPP yang telah disusun guru. 
Dari data yang dapat penulis sampaikan dapat dilihat pada table berikut :

Table 6. Guru menyusun Rencana Program Pembelajaran .

\begin{tabular}{|c|c|c|c|c|}
\hline $\mathrm{NO}$ & Jenjang sekolah & Indikator mata pelajaran & $\begin{array}{l}\mathrm{Ke} \\
\text { tercapaian }\end{array}$ & Ket \\
\hline 1 & TKLB & - & $0 \%$ & $\begin{array}{l}\text { Tidak ada } \\
\text { yang } \\
\text { konsultasi }\end{array}$ \\
\hline 2 & SDLB & $\begin{array}{l}\text { Tematik SDLB, Bina Diri, } \\
\text { Olah Raga dan Kesenian }\end{array}$ & $70 \%$ & $\begin{array}{l}70 \% \text { guru } \\
\text { SDLB } \\
\text { konsultasi } \\
\text { menyusun } \\
\text { RPP }\end{array}$ \\
\hline 3 & SMPLB & $\begin{array}{l}\text { BI,Matematika,IPA,IPS,Bhs } \\
\text { Inggris,PKn }\end{array}$ & $60 \%$ & $\begin{array}{l}60 \% \quad \text { guru } \\
\text { SMPLB } \\
\text { konsultasi } \\
\text { menyusun } \\
\text { RPP }\end{array}$ \\
\hline 4 & SMALB & Bahasa Indonesia & $10 \%$ & $\begin{array}{l}\text { Dari } 3 \\
\text { sekolah } 15 \\
\text { orang } 10 \% \\
\text { yang } \\
\text { melakukan } \\
\text { konsultasi } \\
\text { menyususn } \\
\text { RPP }\end{array}$ \\
\hline & & & & \\
\hline
\end{tabular}

Kriteria :

$90-100=$ sangat baik

$70-89=$ baik

$50-69=$ cukup

$30-49=$ kurang

$0-29$ = sangat kurang 
Diskripsi : bahwa guru di jenjang TKLB masih banyak yang mengalami kesulitan untuk berkomunikasi berdiskusi melalui media maya ( email ) untuk menyusun RPP bahkan tidak ada sama sekali ( 0\%) sangat kurang, Tingkat SDLB (70\%) baik, guru melakukan konsultasi penyusunan RPP dan (60\%) cukup, guru SMPLB telah menyusun RPP baik negeri maupun swasta dan (10\%) sangat kurang guru SMALB yang melakukan konsultasi menyusun RPP melalui media email.

\section{Kendala Yang Dihadapi}

1. Tidak semua kepala sekolah dan guru mengusai Informasi Telekomonikasi ( IT )

2. Tiap-tiap sekolah belum semua memiliki wifi.

3. Dokumen yang harus dibutuhkan secara hard copy yang dibutuhkan pengesahan pejabat atau kepala sekolah dan guru tidak bisa dilakukan.

4. Tidak dapat dilakukan pembinaan apabila ada informasi yang mendesak karena informasi yang sudah di delede / hapus oleh pengguna media blog.

5. Pengguna media maya hanya di senangi para guru/ kepala sekolah usia muda

\section{Alternatif Pengembangan Program Kepengawasan}

Setelah dilakukan refleksi hasil pembinaan, pemantauan dan penilaian dari jenjang TKLB,SDLB, SMPLB dan SMALB penulis merencanakan alternatif pengembangan program Kepengawasan melalui media maya adalah :

1. Supervisi Manajerial : Kualifikasi dan kompetensi tenaga pendidik yaitu Pembinaan penilaian kinerja Kepala Sekolah dari data sekolah yang belum dilakukan penilaian Kinerja Kepala Sekolah yaitu 22 sekolah, dengan mengembangkan sekolah mengaktifkan komunikasi lewat blog atau email dengan alamat MOZAIK PK BWI alamat emailockyzul@yahoo.co.id

2. Supervisi akademik : Perubahan proses pembelajaran yang berbasis kurikulum 2013 dengan pembinaan penyusunan Rencana Program Pembelajaran berbasis Tematik melalui pembinaan pemantauan dan penilaian langsung maupun tidak langsung.

3. Program Pembimbingan dan Pelatihan guru dan Kepala sekolah dalam pelaksanaan kepengawasan baik melalui supervisi langsung maupun tidak langsung, tentang peningkatan 8 Standar Nasional pendidikan terutama supervisi akademik. 


\section{KESIMPULAN}

Berdasarkan hasil best practice dapat disimpulkan sebagai berikut :

1. Aspek Intelektuality dapat di simpulkan bahwa penulis dapat memengaruhi dalam penilaian akreditasi sekolah keberhasilan dari tahun 2012/2013 dan 2013/2014 adalah: TKLB 6,79\%, SDLB 18,75\%, SMPLB 0,3\% dan SMALB 28,75\% meningkatnya pengembangan sekolah berdasarkan 8 Standar Nasional Pendidikan.

2. Aspek Emotionality dan sociability guru dan kepala sekolah dalam pengguna media maya dari jenjang TKLB, SDLB,SMPLB dan SMALB adalah: Komunikasi kepala sekolah dan guru dengan efektif melalui internet, ( dunia maya), hand phone dan multi media yang lain yang diwadahi dengan MOZAIK PK BWI adalah TKLB 20\%, SDLB $33 \%$, SMPLB $45 \%$ dan SMALB 25\%.

3. Aspek Personalability bahwa dari 43 sekolah kepala sekolah yang telah dilakukan penilaian kinerja kepala sekolah adalah 21 sekolah jenjang TKLB,SDLB dan SMALB dengan nilai rerata baik ( 78,49).

4. Aspek moral ability dan physicality dimana pengawas memengaruhi persepsi orang lain tentang kemampuan kepemimpinan bahwa guru di jenjang TKLB masih banyak yang mengalami kesulitan untuk berkomunikasi berdiskusi melalui media maya ( email ) untuk menyusun RPP bahkan tidak ada sama sekali ( 0\%) sangat kurang, Tingkat SDLB (70\% ) baik, guru melakukan konsultasi penyusunan RPP dan (60\%) cukup, guru SMPLB telah menyusun RPP baik negeri maupun swasta dan (10\%) sangat kurang guru SMALB yang melakukan konsultasi menyusun RPP melalui media email.

\section{SARAN}

Dengan program supervisi akademik, menejerial dan program pembimbingan dan pelatihan guru dan kepala sekolah yang telah terlaksana baik secara langsung maupun tidak langsung hendaknya mendapatkan dukungan dari berbagai pihak terutama yaitu:

1. Kepada Kepala Dinas Pendidikan Provinsi agar menambah jumlah pengawas PK-LK agar pelaksanaan kepengawasan di wilayah sekolah binaan lebih optimal.

2. Kepada Kepala Dinas Pendidikan Kota/Kabupaten agar menempatkan pengawas PKLK di daerahnya agar sekolah mendapatkan pembinaan dari pengawas PK-LK daerah secara optimal.

3. Kepada Kepala Sekolah TKLB, SDLB, SMPLB dan SMALB agar meningkatkan komitmen untuk mengembangkan sekolahnya dengan peningkatan kompetensi melalui media maya. 
Pelaksanaan Kepengawasan Melalui Metode Supervisi Tidak Langsung Dengan Pendekatan Leadership 3.0 Pada Sekolah Khusus (Best Practices)

4. Kepada para Guru TKLB, SDLB, SMPLB dan SMALB agar meningkatkan kompetensi baik melalui pelatihan- pelatihan mandiri maupun dari pemerintah agar pelayanan pendidikan kepada Anak Berkebutuhan Khusus lebih efektif dan optimal.

5. Kepada teman pengawas lainnya untuk bekerjasama mengembangkan layanan pendidikan khusus di daerah binaannya.

\section{DAFTAR PUSTAKA}

Keputusan Menpan nomor: 091/KEP/M.PAN/10/2001, Tentang Jabatan Fungsional Pengawas Sekolah dan Angka Kreditnya,Jakarta

Program Kerja Pengawas Sekolah Dinas Pendidikan Provinsi Jawa Timur Tahun Pelajaran 2011/2012, Jakarta

Peraturan Pemerintah No.19 Tahun 2005 tentang Standar Nasional Pendidikan.

Ridwansyah Ardi. 2013. Leadership 3.0, PT Gramedia Pustaka Utama,Jakarta

Surat Tugas Pengawas Sekolah dari Kepala Dinas Pendidikan Propvinsi Jawa Timur

Undang-Undang nomor: 20 tahun 2003 tentang Sistem Pendidikan Nasional, 